\title{
Inhibition Behavior of Compound Corrosion Inhibitors for Carbon Steel
}

\section{in Natural Seawater}

\author{
Fu Qiang ${ }^{1, a}$ and Xiaogang Yang ${ }^{2, b}$ \\ 1.Electric Power Research Institute of Guangdong Power Grid Corporation, Guangzhou 510080, \\ China \\ 2.College of Environment and Safety Engineering, Qingdao University of Science \\ and Technology, Qingdao, 266042, China \\ afuqiang7293@163.com, byxg95@126.com
}

\begin{abstract}
Keywords: corrosion inhibitor, carbon steel, seawater, weight loss, polarization curve
Abstract: A kind of environment-friendly compound corrosion inhibitor has been made from sodium tungstate, sodium silicate, calcium gluconate, sodium polyphosphate and zinc sulfate. The inhibition capability of the corrosion inhibitor in seawater for carbon steel is carried out by weight-loss method and electrochemical method. The effect of different inhibitors concentration on the corrosion efficiency is also studied. The results show that the presence of these compounds in seawater suppresses cathodic processes and when the dosage of sodium tungstate is $80 \mathrm{mg} / \mathrm{L}$, sodium silicate is $20 \mathrm{mg} / \mathrm{L}$, calcium gluconate is $40 \mathrm{mg} / \mathrm{L}$, sodium polyphosphate is $60 \mathrm{mg} / \mathrm{L}$ and zinc sulfate is $60 \mathrm{mg} / \mathrm{L}$, the corrosion inhibition effects of carbon steel are pretty good. Carbon steel corrosion inhibition efficiency reaches $92.53 \%$ in seawater for 15 days.
\end{abstract}

\section{Introduction}

With fresh water resource growing shortage, it is significant to utilize seawater instead of fresh water as supplement water of recirculating cooling water system. ${ }^{[1]}$ Seawater as industrial circulating cooling water can relieve the contradiction between shortage of fresh water and rapid development of industries effectively. ${ }^{[2]}$ But seawater is electrolyte solution with multiple salts, mainly $3.0 \% \sim 5.0 \%$ sodium chloride, $\mathrm{pH}$ value about 8 , and dissolving a certain oxygen. ${ }^{[3]}$ Due to the above reasons, seawater easily leads to pipeline and heat exchanger in the recirculating cooling water system corrosion. So the key of seawater utilization is to solve piping and equipment corrosion problem in the seawater environment. In the recirculating cooling water system materials, mild steel is used generally owing to its excellent mechanical properties and low cost. Corrosion and corrosion inhibition of steel have received enormous attention in recirculating cooling water system. $^{[4,5]}$ The common methods to control and prevent metal equipment corrosion have using resistant material, using cooling water anticorrosion coating, increasing $\mathrm{pH}$ value of the cooling water operation and adding corrosion inhibitor. ${ }^{[6-9]}$ Among these methods using resistant material can protect metal equipment effectively, but the previous expenses is too high. The technology of anticorrosion coating method is complex and this method applies to local anticorrosion in the system. Increasing cooling water $\mathrm{pH}$ value makes mild steel deactivation easily. Adding corrosion inhibitor can protect the whole system and it is economical and practical. ${ }^{[10,11]}$ At present it is widely used method.

The development of seawater corrosion inhibitor undergoes from inorganic to organic, from single to compound, from single inhibition type to mixed inhibition type and other electrochemistry method combination process. ${ }^{[12-14]}$ Many organic molecules exhibit high anticorrosion potential, but they pollute the environment during their synthesis and applications. ${ }^{[15-18]}$ The effect of single seawater corrosion inhibitor is unsatisfactory in general, so two types or several types compound coordinate use to improve inhibition efficiency. 
The aim of the present work is to study the effect of compound corrosion inhibitors for carbon steel in natural seawater for 15 days using weight loss and electrochemical polarization curve measurements. The effect of inhibitors concentrations on the inhibition efficiency of carbon steel in free and inhibited natural seawater was also investigated.

\section{Experimental Procedure}

\section{Materials}

The steel used in this study is a carbon steel(Q235 carbon steel) with a chemical composition (in wt $\%$ ) of $0.14-0.22 \% \mathrm{C}, 0.3-0.65 \% \mathrm{Mn}, \leq 0.3 \% \mathrm{Si}, \leq 0.05 \% \mathrm{~S}, \leq 0.045 \% \mathrm{P}$, and the remainder Fe. The size of sample is about $5 \mathrm{~cm} \times 2.5 \mathrm{~cm} \times 0.3 \mathrm{~cm}$ (length $\times$ wide $\times$ thick). The carbon steel samples were pre-treated prior to the experiments by polishing with silicon carbide paper (240, 600, and 800), then rinsed with absolute ethyl alcohol, degreased in acetone for 5 minute, blown dry with cold air blast, and then dried in desiccator at room temperature for 6 hours. After dried, the samples were weighed and measured length, wide and thick to calculate sample area. The corrosion inhibitors were sodium tungstate, sodium silicate, calcium gluconate, sodium polyphosphate and zinc sulfate. These corrosion inhibitors were remixed with different dosages in order to find out the optimum proportional relation. The natural seawater chose from Qingdao First Bathing Beach waters.

\section{Measurements}

\section{Weight loss measurements}

The experiment was carried out in a beaker containing 1L natural seawater. Three clean preweighed carbon steels as duplicate samples were immersed completely in $1 \mathrm{~L}$ natural seawater with and without the addition of different concentrations of corrosion inhibitors at room temperature (298K). After 15 days immersion in natural seawater, the specimens were withdraw, rinsed with pickling solution, washed with acetone, dried, and weighed. The inhibition efficiency (IE\%) was calculated as Eq.1:

$\operatorname{IE}(\%)=\left[\left(\mathrm{V}_{0}-\mathrm{V}\right) / \mathrm{V}_{0}\right] \times 100$

where $\mathrm{V}_{0}$ and $\mathrm{V}$ are the corrosion rate of the mild carbon steel in the absence and presence of inhibitor, respectively.

Corrosion rate (V) was calculated as Eq.2:

$\mathrm{V}=\left(\mathrm{W}_{0}-\mathrm{W}_{1}-\mathrm{W}_{2}\right) / \mathrm{A} \cdot \mathrm{t}$

where $\mathrm{W}_{0}, \mathrm{~W}_{1}$ and $\mathrm{W}_{2}$ are the sample original weight, the same sample weight after removal of corrosion products and the blank sample correction weight loss (weightlessness in air) respectively. A is the sample area. $t$ is experimental period.

Electrochemical polarization curve measurements

Electrochemical studies were carried out using CS multi-channel electrochemical workstation. A three-electrode cell system was employed for the measurement; mild steel with an exposed area of $1 \mathrm{~cm}^{2}$ acts as a working electrode, whereas platinum wire and saturated calomel electrode acts as a counterelectrode and reference electrode, respectively. The measurements were performed in natural seawater with and without the addition of different inhibitor concentrations in an aerated environment. All polarization curves were recorded at room temperature $298 \mathrm{~K}$, and the electrodes 
were immersed in the test solution for 30 minutes at natural potential to attain steady state before measurement.

\section{Results and discussion}

Effect of sodium tungstate concentration on inhibition efficiency and polarization curves From the inhibition efficiencies obtained from the weight loss experiments for mild steel in natural seawater, it is found that the inhibition efficiency is highest with sodium tungstate concentration $80 \mathrm{mg} / \mathrm{L}$ and other inhibitors concentration the same, which is evident from Fig. 1 (a). Sodium tungstate belongs to cathode type inhibitor, which can be obtained from Fig. 1 (b). Sodium tungstate not only can be used as inhibitor of metal uniform corrosion to change metal activation polarization property, but also can restrain metal pitting. According to the passivation film theory, sodium tungstate does not cover whole surface, but plays filling gap and mending defect role to oxidation film.

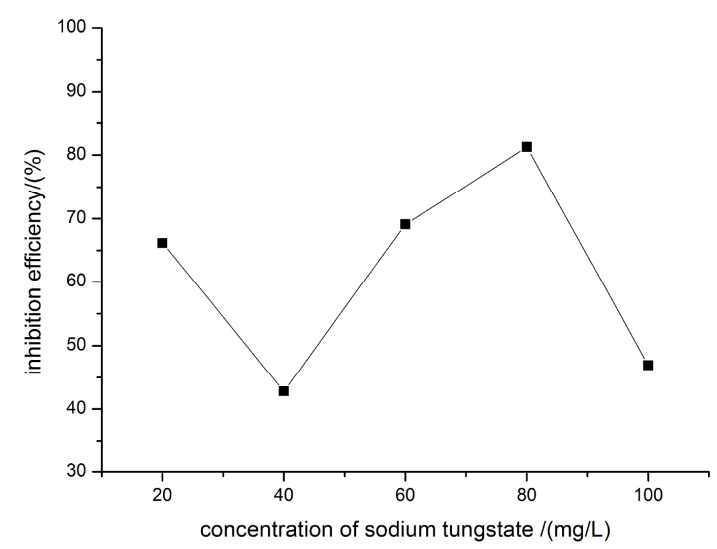

(a)

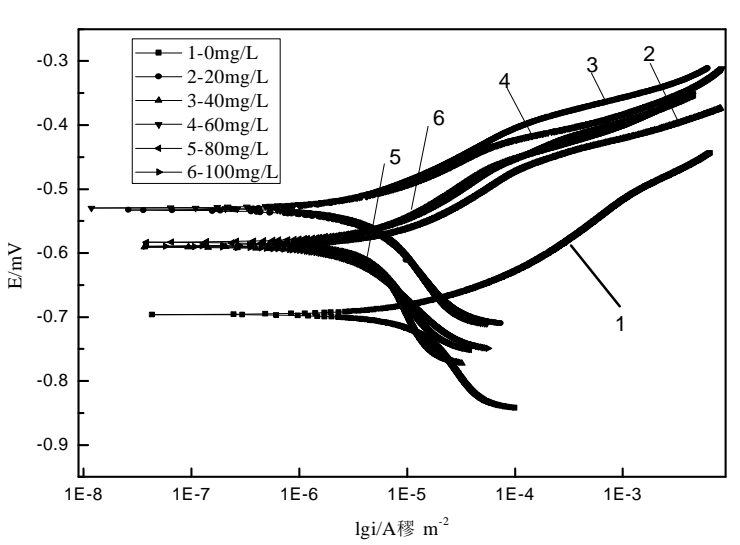

(b)

Fig. 1 Effect of sodium tungstate concentration on inhibition efficiency (a) and polarization curves (b) on mild steel in natural seawater of 15 days

\section{Effect of calcium gluconate concentration on inhibition efficiency and polarization curves}

From Fig. 2(a) it is shown when calcium gluconate concentration is $40 \mathrm{mg} / \mathrm{L}$, the inhibition efficiency is highest, and the change rule of inhibition efficiency is not proportional to calcium gluconate concentration. Fig. 2(b) shows that calcium gluconate is also cathode type inhibitor.

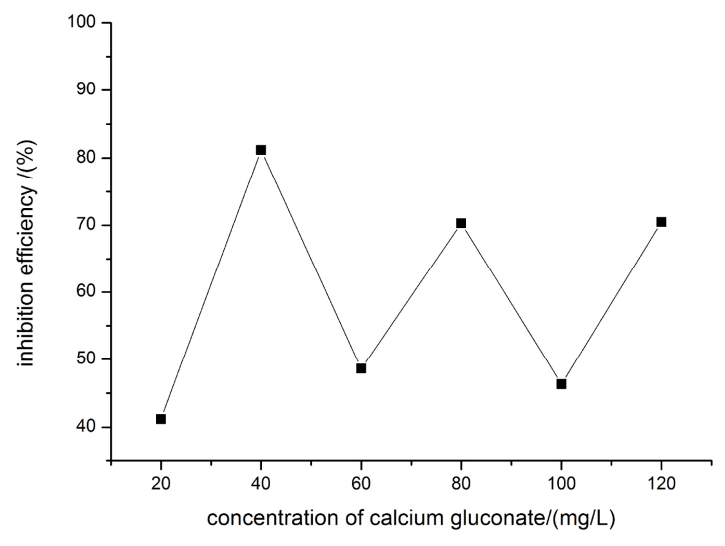

(a)

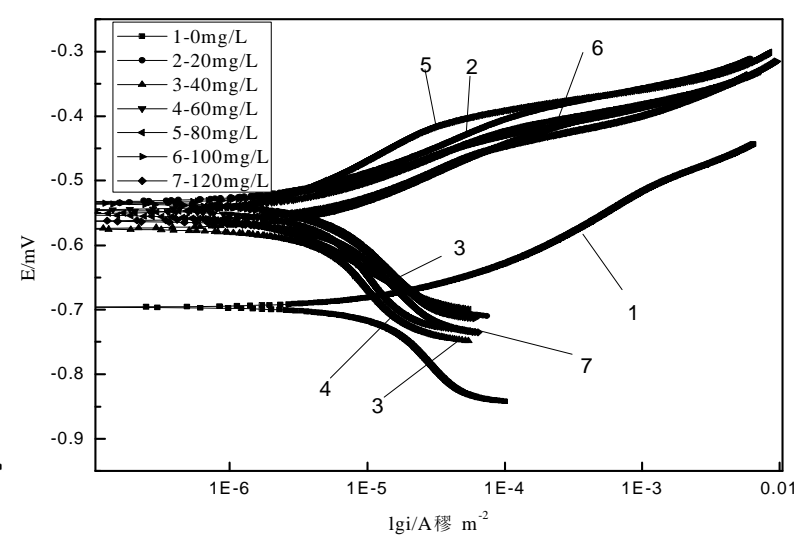

(b)

Fig. 2 Effect of calcium gluconate concentration on inhibition efficiency (a) and polarization curves (b) on mild steel in natural seawater of 15 days

\section{Effect of zinc sulfate concentration on inhibition efficiency and polarization curves}

Also through the weight loss experiments, it is found that the inhibition efficiency basically increases with increase in zinc sulfate concentration, but after zinc sulfate concentration is more 
than $60 \mathrm{mg} / \mathrm{L}$, the inhibition efficiency increases insignificantly, which is obvious from Fig. 3(a). The optimum concentration of zinc sulfate chooses $60 \mathrm{mg} / \mathrm{L}$. Fig. 3(b) shows that inhibition mechanism is cathode type inhibition. Zinc ion of zinc sulfate can form zinc hydroxide rapidly in water depositing cathode surface to play a protective role. Zinc sulfate forms film quickly, but the film does not firm, so it is often used compounding with other inhibitors.

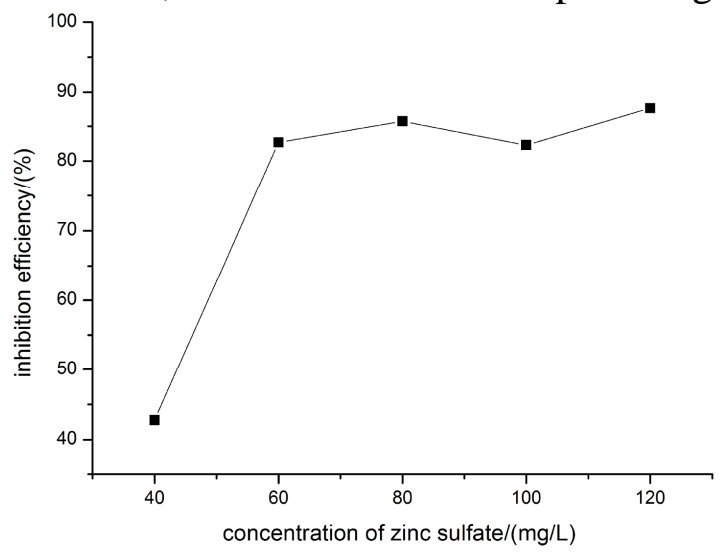

(a)

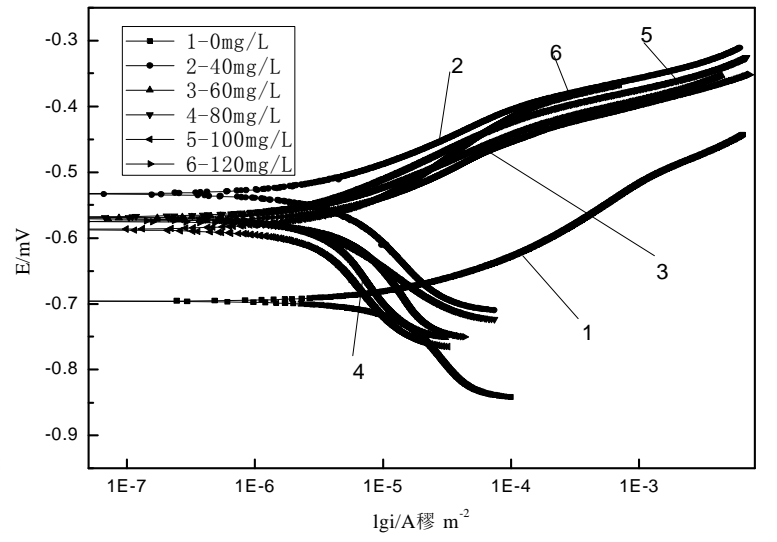

(b)

Fig. 3 Effect of zinc sulfate concentration on inhibition efficiency (a) and polarization curves (b) on mild steel in natural seawater of 15 days

\section{Effect of sodium polyphosphate concentration on inhibition efficiency and polarization curves} It can be seen from Fig. 4(a) that sodium polyphosphate concentration has obvious effect on inhibition efficiency. When the concentration is $60 \mathrm{mg} / \mathrm{L}$, the inhibition efficiency is the lowest. The inhibition efficiency increases with increase in sodium polyphosphate concentration more than $60 \mathrm{mg} / \mathrm{L}$. Sodium polyphosphate can coordinate with divalent iron ions and tervalence iron ions to form sodium ferric polyphosphate coordination ion and form compact precipitation film by current electrodeposition on cathode surface. Overall considerration the concentration of sodium polyphosphate chooses $100 \mathrm{mg} / \mathrm{L}$. Fig. 4(b) indicates that sodium polyphosphate is typical cathode precipitation type inhibitor.

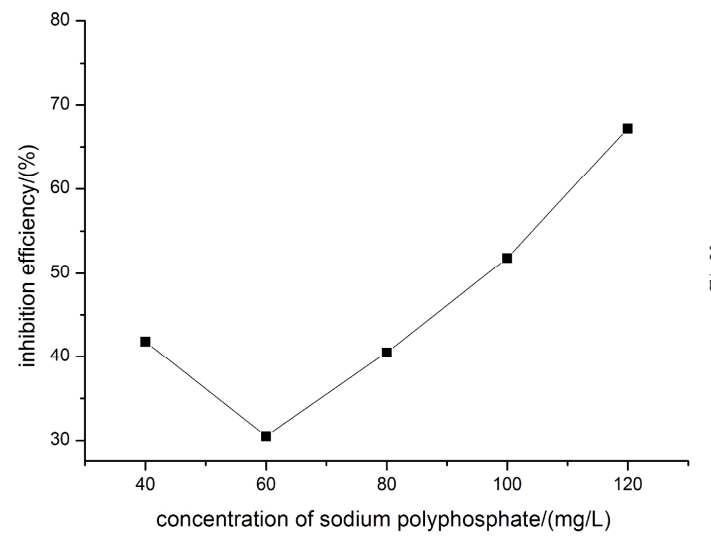

(a)

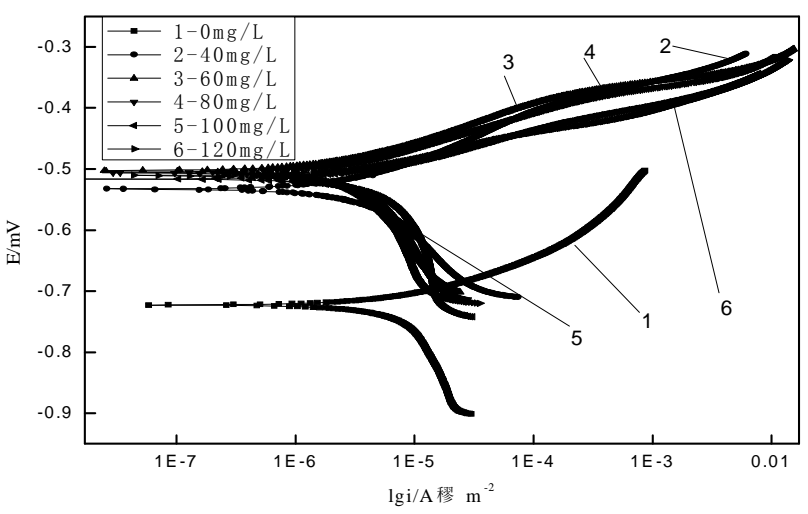

(b)

Fig. 4 Effect of sodium polyphosphate concentration on inhibition efficiency (a) and polarization curves

(b) on mild steel in natural seawater of 15 days

\section{Effect of sodium silicate concentration on inhibition efficiency and polarization curves}

Sodium silicate can be used as adsorption type inhibitor and its protection role lies in forming silicon protection film on steel surface. The film is silica gel film consisting of metal corrosion, calcium and magnesium elements and so on. After the film forms, metal isolates from corrosion medium and the corrosion stops. Fig. 5 (a) shows when sodium silicate concentration is $20 \mathrm{mg} / \mathrm{L}$, the inhibition efficiency is the highest. But the effect of sodium silicate on the inhibitor efficiency is 
not evident comparing with the former four kind inhibitors. Fig. 5 (b) also proves sodium silicate is a kind of cathode type inhibitor.

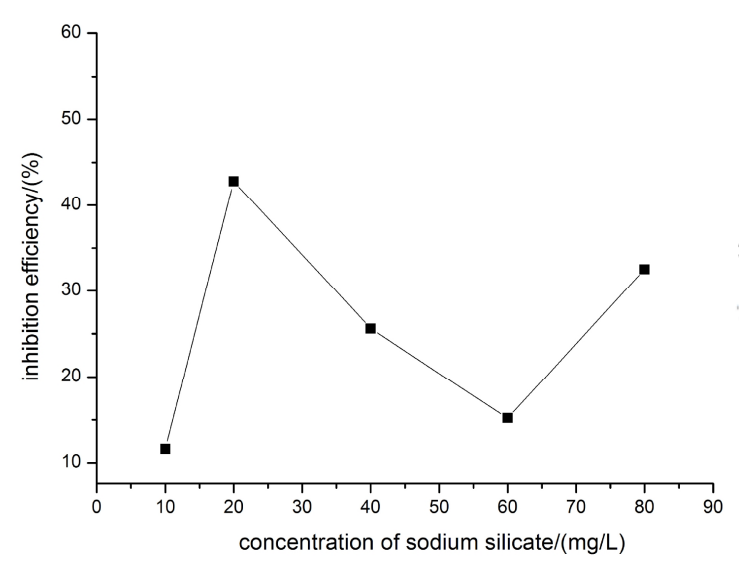

(a)

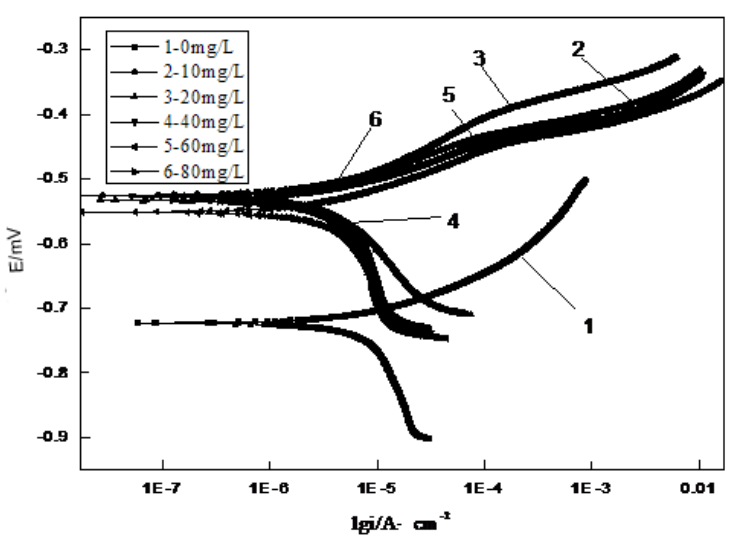

(b)

Fig. 5 Effect of sodium silicate concentration on inhibition efficiency (a) and polarization curves (b) on mild steel in natural seawater of 15 days

By weight-loss measurement, the optimal inhibition efficiency reaches $92.53 \%$ with compound inhibitor components and concentrations as sodium tungstate $80 \mathrm{mg} / \mathrm{L}$, sodium silicate $20 \mathrm{mg} / \mathrm{L}$, calcium gluconate $40 \mathrm{mg} / \mathrm{L}$,sodium polyphosphate $60 \mathrm{mg} / \mathrm{L}$ and zinc sulfate $60 \mathrm{mg} / \mathrm{L}$ at room temperature for 15 days.

\section{Conclusions}

The corrosion behavior of carbon steel is investigated in natural seawater with and without addition of various concentrations of compound inhibitors, using weight- loss and electrochemical techniques. Sodium tungstate, sodium silicate, calcium gluconate, sodium polyphosphate and zinc sulfate are found to be good adsorption inhibitor for the corrosion of carbon steel in natural seawater. The polarization curves indicate that sodium tungstate, sodium silicate, calcium gluconate, sodium polyphosphate and zinc sulfate affect cathodic Tafel slopes, and are thus a mixed type inhibitor. The inhibition is due to the adsorption of the inhibitor molecules on the carbon steel surface and blocking of active sites. The inhibitor concentration has important effect on the inhibition efficiency. When the dosage of sodium tungstate is $80 \mathrm{mg} / \mathrm{L}$, sodium silicate is $20 \mathrm{mg} / \mathrm{L}$, calcium gluconate is $40 \mathrm{mg} / \mathrm{L}$,sodium polyphosphate is $60 \mathrm{mg} / \mathrm{L}$ and zinc sulfate is $60 \mathrm{mg} / \mathrm{L}$, the corrosion inhibition effects of carbon steel are pretty good. Carbon steel corrosion inhibition efficiency reaches $92.53 \%$ in seawater for 15 days.

\section{References}

[1] X. Joseph Raj., N. Rajendran., Protection of Metals and Physical Chemistry of Surfaces, 2013, 49, $763-775$

[2] Saedah R. Al-Mhyawi, African Journal of Pure and Applied Chemistry.2014,8,9.

[3] M. Larif. A., Elmidaoui. A., Zarrouk. H. Res Chem Internmed, 2013, 39, 2663

[4] Saremi, M., Dehghanian, C., Sabet, M. M. Corros. Sci., 2006,48,1404.

[5] Eddy, N.O., Odoemelam, S. A.,Odiongenyi, A. O., Green Chem. Lett. Rev,2009,

2,111

[6] Abiola, O.K., Otaigbe, J.O,E, Int. J. Electrochem. Sci., 2008,3,191.

[7] Chowdhary, R., Jain, T., Rathoria, M. K., Mathur, S.P.,Bull. Electrochem, 2004,20, 67.

[8] Alentejano R. C., Aoki V. I.,Electrochimica Acta, 2004,49,17.

[9] Silva J. W. J.,Codaro E. N., Nakazato R. Z., Applied Surface Science, 2005, 252, 1117. 
[10] Mu G. N., Li X. H., Qu Q., Corrosion Science, 2006, 48, 445.

[11] Oguzie, E. E.,Chem. Phys., 2006, 99, 441 .

[12] Larabi, L., Harek, Y., Benali, O., Ghalem, S., Prog. Org. Coat, 2005, 54, 256.

[13] Bouklaha, M., Hammouti, B., Aounitia, A., Benhaddab, T., Prog. Org. Coat., 2004, 49, 225.

[14] Varara, S., Mursesan, L.M., Rahmouni, K., Takenouti, H., Corrosion Sci., 2008,50, 2596

[15] Mansfeld, F. and Smith, T., Corrosion, 1973,29,105.

[16] Ravichandra, n R., Nanjundan, S., Rajendran, N,.J. Appl. Electrochem., $\quad$ 2004, 34, 117.

[17] Ravichandra, n R., Nanjundan, S., Rajendran, N,.Appl. Surf. Sci., 2004, 236, 241.

[18] Bentiss, F., Traisnel, M., and Lagrene, M.J., Appl. Electrochem., 2001, 31, 41. 